\title{
História da Comunicação 0 tempo: a lógica do ininterrupto
}

DOI: https://doi.org/10.35168/2176-896X.UTP.Tuiuti.2020.Vol7.N62.pp64-97

Geraldo Pieroni

Professor da Universidade Tuiuti do Paraná (UTP), Curitiba, PR, Brasil. Doutorado em História. Université Paris-Sorbonne, PARIS 4, França. Mestrado em História. Universidade Federal da Bahia, UFBA, Brasil. Mestrado em História. Université ParisSorbonne, PARIS, França. E-mail: geraldo.pieroni@utp.brOrcid: https://orcid.org/0000-0002-1896-8373

Carlos Manoel Machado Guimarães Filho Federação da Agricultura do Estado do Paraná, FAEP, Brasil. Graduação em Comunicação Social - Jornalismo, Pontifícia Universidade Católica do Paraná, PUC/PR, Brasil.

Dalvan Alves Siteneski Graduação em Comunicação Social - Publicidade e Propaganda. Universidade de Passo Fundo, UPF, Brasil. Mestrado em andamento em Comunicação e Linguagens. Universidade Tuiuti do Paraná, UTP, Brasil. E-mail: dalvan_as@hotmail.com

Elaine Polo Fortunato Instituto Federal do Paraná. Câmpus Palmas. Paraná. Graduação em Pedagogia. Centro Universitário Diocesano do Sudoeste do Paraná, UNICS, Brasil. E-mail: elaine.fortunato@ifpr.edu.br.

Maurício Ferreira Santana Mestrado em Teoria Literária. Centro Universitário Campos de Andrade, UNIANDRADE, Brasil. Doutorado em andamento em Comunicação e Linguagens. Universidade Tuiuti do Paraná, UTP, Brasil. Orcid: https://orcid.org/0000-0003-1937-1963

Ricardo Uhry Mestrado em Administração.Universidade Federal do Paraná, UFPR, Brasil. Doutorado em andamento em Comunicação e Linguagens. Universidade Tuiuti do Paraná, UTP, Brasil. E-mail: ricardo_uhry@yahoo.com.br.

Orcid: https://orcid.org/0000-0001-6296-7258

Vitor Emanuel Pinto Cardoso Graduação em Psicologia.Universidade da Amazônia, UNAMA, Brasil. Mestrado em andamento em Comunicação e Linguagem. Universidade Tuiuti do Paraná, TUIUTI, Brasil. Orcid: https://orcid.org/0000-0001-6430-4044

Revista Tuiuti: Ciência e Cultura, v.7 n.62. p. 64-97, Curitiba, 2021 


\title{
História da Comunicação 0 tempo: a lógica do ininterrupto
}

O tempo é um objeto natural, um aspecto dos processos naturais, um objeto cultural? Ponderou Norbert Elias ${ }^{1}$. Para ele o tempo é uma instituição cuja postura varia conforme o estágio de desenvolvimento atingido pelas sociedades:

\begin{abstract}
"o indivíduo ao crescer, aprende a interpretar os sinais temporais usados em sua sociedade e a orientar sua conduta em função deles (...) A imagem mnêmica, ou seja referente à memória e a "representação do tempo num determinado indivíduo dependem, pois, do nível de desenvolvimento das instituições sociais que representam o tempo e difundem seu conhecimento, assim como das experiências que o indivíduo tem delas desde a mais tenra idade" (ELIAS, 1998, p. 15).
\end{abstract}

O "presente perpétuo, esta percepção de que estamos inseridos no universo contemporâneo da formulação de um inédito regime de historicidade localizado no presente."². O presente se desgasta na ação imediata apressada pela contínua mudança, uma espécie de presentismo. Todo e qualquer instante "se transforma em tempo de frenesi que dura continuamente"3, Este continuado tempo nos meios de comunicação "é marcado pelo fluxo continuo da informação, instaurando um tempo novo governado pela lógica do ininterrupto"4.

Focalizando temporalidades múltiplas, o presente artigo reúne seis textos que se inserem na práxis dos estudos referentes à História da Comunicação e suas múltiplas possibilidades de análises. Estas pesquisas, sejam elas específicas em uma determinada temporalidade ou alargando os limites tempo/espaço, incidem no universo da comunicação enquanto lugar social.

1 Norbert Elias. Sobre o tempo. Zahar Ed. Rio de Janeiro: 1998, p. 14.

2 F. Hartog. Regime de historicidade: presentismo e experiência do tempo. Belo Horizonte: Ed. Autêntica, 2014, P. 31

3 Mariavalva Barbosa. Tempo, tempo histórico e tempo mediático, in: MUSSE, VARGAS, NICOLAU, (org). EDUFBA, 2017, p 20. Comunicação, mídias e temporalidades, COMPÓS.

4 Mariavalva Barbosa, op.cit., p 21). Ver (MARQUIONI e PIERONI: Das redenições da noção de duração'na duração' Apontamentos para o lançamento de âncoras temporais nas análises comunicacionais em tempos acelerados. ALCEU - Revista de Comunicação, Cultura e Política - Departamento de Comunicação Social da PUC-Rio, V. 20, N.. 41 (2020), Ed. 41, Dossiê Narrativas midiáticas: tempo presente e história cultural. 


\section{História da Comunicação 0 tempo: a lógica do ininterrupto}

Os textos abaixo foram apresentados e discutidos no Seminário de História da Comunicação (2020) realizado pelo Programa de Pós-Graduação em Comunicação e Linguagem da Universidade Tuiuti do Paraná.

Geraldo Pieroni - PPGCom/UTP

\section{Representação Sindical Rural: história e confluência}

\section{Carlos Manoel Machado Guimarães Filho5}

No Brasil, a necessidade da construção da representatividade rural por parte de uma entidade sindical e a manutenção de uma identidade junto aos produtores rurais ocorreram influenciadas por diversos fatores, como a midiatização das ações realizadas e as estratégias de comunicação. Esse artigo é centrado no fato que a representatividade rural foi forjada desde o início do século XX. E, ainda, de que esse processo seja contínuo na atualidade e sustentado por um conjunto de práticas comunicacionais. A discussão é centrada no fortalecimento da representação sindical rural a partir do uso dos veículos de comunicação como táticas de mobilização dos produtores rurais.

No século 20, principalmente nas primeiras décadas, o desafio da construção da representatividade entre os produtores rurais no Brasil ultrapassou o processo da regulamentação por parte de órgãos oficiais. O contexto era de intensa transformação social e também fornecimento de novas tecnologias para a aplicação no cotidiano da sociedade. A partir de marcos

5 Mestrando em Comunicação e Linguagens pela Universidade Tuiuti do Paraná (UTP), Brasil. E-mail: cguimaraesfilho@hotmail.com 


\section{História da Comunicação 0 tempo: a lógica do ininterrupto}

regulatórios, como decretos e leis, o sindicalismo rural passou a se consolidar no país. Apesar da dificuldade de acesso às zonas rurais, era nesses espaços que se buscava o engajamento dos produtores rurais nos diversos estados brasileiros para uma mobilização coletiva em prol da defesa dos direitos e interesses dos agricultores, pecuaristas e demais trabalhadores do agronegócio ${ }^{6}$ nacional.

O processo se deu de modo diferente daquele observado em relação aos movimentos urbanos, que já no início do século 20, mais exatamente em 1906, estavam consolidados e mobilizavam mais de 100 mil trabalhadores. Principalmente por causa de insatisfações com a política governamental, três anos antes, em 1903, os trabalhadores rurais registravam as primeiras tentativas de organização sindical, porém, ainda de forma tímida e desorganizada (THOMAZ JÚNIOR, 1998). Apesar dos esforços, as quatro primeiras décadas do século 20 não registraram importantes avanços na organização do setor rural. Foi somente no final da década de 1940 que surgiram as primeiras organizações de trabalhadores no campo. Isso porque o Decreto-Lei $7083^{7}$, do então presidente Getúlio $\operatorname{Vargas}^{8}$, passava a autorizar a organização sindical rural.

A partir dessa permissão, houve um crescimento exponencial no número de sindicatos rurais no Brasil. Em meados de 1963, o país registrava 800 entidades sindicais rurais e cerca de 500 mil trabalhadores do setor mobilizados ${ }^{9}$. No ano seguinte, em 1964, o número de sindicatos chegou a 1,2 mil e 42 federações se estabeleceram, em praticamente todos os Estados do Brasil.

\footnotetext{
60 termo agronegócio surgiu da variação do inglês "agribusiness". Popularizado, 0 termo se refere ao conjunto de operações da cadeia agropecuária, observando desde o trabalho dentro da propriedade até a comercialização dos produtos.

70 Decreto-Lei, datado de 10 de novembro de 1944, permitia "[...] a associação para fins de estudo, defesa e coordenação de seus interesses econômicos ou profissionais, de todos os que, como empregadores ou empregados, exerçam atividades ou profissão rural". Ainda, segundo a lei, "[...] os sindicatos rurais serão organizados normalmente reunindo exercentes de atividades ou profissões idênticas, similares ou conexas [...]".

8 Getúlio Vargas governou 0 Brasil por 15 anos, de forma contínua, de 1930 a 1945. Esse período foi um marco na história brasileira, em razão de mudanças feitas no país, tanto sociais quanto econômicas. Vargas sempre esteve voltado para o desenvolvimento, principalmente no meio rural. Inclusive, mundialmente, o país carrega o rótulo de "Celeiro do Mundo", expressão dita pela primeira vez por Vargas. Na época, 0 objetivo do slogan nacional era definir o potencial agrícola do Brasil

9 De acordo com dados do Instituto Brasileiro de Geografia e Estatística (IBGE, s/d), a população do Brasil na década de 1970 era de 72,1 milhões de pessoas.
} 


\section{História da Comunicação 0 tempo: a lógica do ininterrupto}

Ainda, nesse contexto, é preciso destacar o papel da chamada Revolução Verde ${ }^{10}$ no país. No início da década de 1970, esse conjunto de iniciativas encetou uma mudança no agronegócio brasileiro, a partir do momento em que agricultores e pecuaristas passaram a ter acesso a ferramentas, tecnologias e métodos que propiciaram o crescimento da produção nacional de alimentos. Inclusive, a Revolução Verde permitiu que o Brasil deixasse a posição de importador de alimentos para se transformar em uma potência do agronegócio, tornando-se líder e/ou ocupando as primeiras colocações no ranking global na produção de soja, milho, feijão, frango, suíno, peixe, banana, laranja, entre outros produtos agropecuários. O crescimento, tanto tecnológico, quanto informativo, também alavancou o engajamento sindical.

Diante de uma revolução, a representatividade sindical rural no Brasil passou ao uso de táticas de comunicação neste processo de, no primeiro momento, mobilização, e, posteriormente, fortalecimento junto ao público-alvo, no caso, os agricultores e pecuaristas. Esse modelo permitiu a formação de redes de produtores rurais e, mais que isso, o aumento do engajamento em prol de interesses coletivos, a ponto de colaborar para uma mobilização global. Afinal, "a mídia adiciona certo dinamismo e mobilidade ao ritmo da vida diária, ao mesmo tempo estendendo e amplificando redes existentes e as formas de fazer as coisas" (DEUZE, 2013).

A construção da representatividade de um determinado público-alvo por parte de uma entidade sindical (independentemente do setor econômico, político, ambiental, financeiro e/ou social) ocorre, entre outros fatores, pela comunicação das ações realizadas em defesa dos interesses daquele setor. Além de ser uma ação desenvolvida em longo prazo, podendo levar, inclusive, anos ou até mesmo décadas, esse trabalho exige "táticas" de comunicação sólidas que se fazem necessárias para a criação e manutenção de uma identidade junto ao coletivo.

10 De acordo com a série histórica da Companhia Nacional de Abastecimento (Conab), a Revolução Verde permitiu um crescimento das atividades rurais, tanto agrícolas como pecuárias, em território brasileiro, além de uma mais eficiente conservação de recursos naturais e ambientais como a água, as florestas e o solo. A Revolução Verde garantiu ao agronegócio brasileiro um crescimento responsável por colocar o país entre os maiores produtores de grãos, hortifrútis e proteínas animais do mundo, posição essa mantida até a atualidade, de acordo com dados da Organização das Nações Unidas para a Alimentação e a Agricultura (FA0, s/d). 


\section{História da Comunicação 0 tempo: a lógica do ininterrupto}

Independentemente da época, a maneira de se comunicar com os produtores rurais precisa acontecer de forma direta, mas considerando peculiaridades do meio rural. A representatividade da Federação da Agricultura do Estado do Paraná (FAEP) ${ }^{11}$ foi constituída, junto aos milhares de produtores paranaenses, ao longo das últimas seis décadas, mais precisamente desde a sua criação.

A década de 1960, época na qual a FAEP foi fundada, registrou grandes mudanças políticas e sociais e de efervescência cultural tanto no Brasil como no mundo. Além da inauguração da cidade de Brasília, a nova capital do país, no campo político, o Brasil passou por grandes transformações. Dez presidentes ocuparam o cargo, sucessão nem sempre ocorrida de forma pacífica, enquanto o sistema de governo oscilava entre o presidencialismo, o parlamentarismo, a democracia e a ditadura. Entre esses e tantos outros eventos que foram cruciais para a história contemporânea do Brasil e, certamente, influenciaram, direta ou indiretamente, no fortalecimento das organizações sindicais brasileiras e no surgimento de instituições como a FAEP.

Obviamente, a FAEP se valeu dos meios de comunicação disponíveis na época para esclarecer seu propósito e divulgar os serviços que prestava aos produtores e trabalhadores rurais do Estado do Paraná. Esse material pode e deve ser analisado de forma a clarificar sua influência nas táticas de comunicação utilizadas pela instituição ao longo das suas seis décadas de existência.

A força dessa função representativa da FAEP no setor do agronegócio não foi construída apenas na atualidade. Mas, como aponta Foucault (1996), cada época constrói, a partir de um conjunto de práticas, um rosto histórico. E esse trabalho, entre outros fatores, teve a comunicação, ou melhor, a midiatização, como um dos pilares.

11 Conforme consta no site da Federação da Agricultura do Estado do Paraná, disponível em <www.sistemafaep.org.br>, a entidade "tem como objetivo institucional o estudo, a coordenação, defesa e representação legal da categoria econômica rural, tal como agricultura e pecuária, buscando soluções para as questões relacionadas aos interesses econômicos, sociais e ambientais do produtor". 0 campo de atuação da FAEP é institucional, ou seja, a defesa e a representação legal dos milhares de agropecuaristas. Criada em 1965, a FAEP também tem um papel importante na difusão de informações aos produtores rurais e de articulação com os 152 sindicatos rurais do Paraná. Ainda, a entidade éa responsável por diversas articulações de interesse do setor rural junto as esferas municipal, estadual e federal dos poderes executivo, judiciário e legislativo. 


\section{História da Comunicação 0 tempo: a lógica do ininterrupto}

A imagem da FAEP, junto aos agricultores e pecuaristas paranaenses, não foi forjada na atualidade. Mas sim, formado e transformado ao longo das últimas quase seis décadas. Como Barbosa (2012) faz questão de enfatizar, "pensar comunicação há que obrigatoriamente inserir o passado. Os atos comunicacionais duradouros dos homens (aqui tomamos a liberdade para trocar por instituições) do passado chegam até o presente e deles a história se apropria”.

Assim, o surgimento e fortalecimento da representatividade rural no Brasil, em especial da FAEP junto aos produtores rurais do Paraná, ocorreram com o uso dos veículos de comunicação. Afinal, esses serviram de canais para informação ações e atuações. $O$ ato de comunicar, ao longo das últimas décadas, ajudou a nortear as escolhas e suas rotinas dos agricultores e pecuaristas. Mais que isso, esse trabalho permitiu uma mobilização coletiva, a formação de redes e, consequentemente, o aumento do engajamento em prol de interesses coletivos.

\section{Referências}

BARBOSA, Marialva. Comunicaşão e história: presente e passado em atos narrativos. Comunicação, mídia e consumo. São Paulo: vol. 6, n. 16, p. 11-27, jul. 2009.

BARBOSA, Marialva. Comunicaşão e Usos do Passado. Cultura Pop e Linguagem de Videoclipe. Ed. Logos. São Paulo: edição 42, v. 22, n. 1, 2015.

BARBOSA, Marialva. O presente e o passado como processo comunicacional. In: Revista Matrizes, v. 5, no2, p. 145-155, 2012.

DEUZE, Mark. Viver como um zumbi na mídia lé o único meio de sobreviver. Universidade de São Paulo. São Paulo. Matrizes, vol. 7, núm. 2, pp. 113-129, 2013.

FOUCAULT, Michel. As palavras e as coisas: uma arqueologia das ciências humanas. $8^{\mathrm{a}}$ ed. São Paulo: Martins Fontes, 1999. 


\section{História da Comunicação 0 tempo: a lógica do ininterrupto}

THOMAZ JÚNIOR, Antonio. O sindicalismo rural no Brasil, no rastro dos antecedentes. Revista Electrónica de Geografía y Ciencias Sociales.

Universidade de Barcelona No15, 15 de janeiro de 1998. Disponível em: < http:/ /www. ub.edu/geocrit/sn-15.htm\#N_6_>. Acesso em: 12 setembro. 2020.

\section{A historicidade enquanto personagem drag queen de Pabllo Vittar}

\section{Dalvan Alves Siteneski ${ }^{12}$}

A Drag Queen brasileira Pabllo Vittar - Phabullo Rodrigues da Silva ${ }^{13}$-, ganhou notoriedade em 2015 através do Youtube com a música Open Bar; uma versão da música Lean On do grupo Major Lazer ${ }^{14}$ e Dj Snake ${ }^{15}$ com a participação da cantora MØ. Desde então sua popularidade vem aumentando, esse crescimento é comprovado a partir da sua intensa presença no ambiente midiático e nas redes sociais, sejam eles mainstream ou em espaços culturais alternativos, como vídeos de fãs publicados na internet. Seus videoclipes batem recordes de visualização, também possui recordes de seguidores no Instagram e várias semanas entre os mais ouvidos na plataforma Spotify. Pablo estrelou diversas campanhas publicitárias, participando de vários programas de televisão (ROCHA; POSTINGUEL, 2017). Este texto tem como objetivo delinear cronologicamente o percurso da personagem no cenário brasileiro, uma vez que ela é objeto da pesquisa em desenvolvimento do autor. Para tal delineamento, foram utilizadas matérias jornalísticas de alguns veículos da imprensa nacional e internacional.

12 Mestrando em Comunicação e Linguagens pela Universidade Tuiuti do Paraná (UTP). dalvan_as@hotmail.com

13 No início de sua carreira, a artista usa o nome'Pabllo Knowles' em referência ao sobrenome da cantora Beyoncé. Essa mudança no nome, foi realizada para evitar que a cantora americana Beyoncé Knowles a processasse judicialmente (MARTINS, 2017).

14 Trata-se de um grupo de música eletrônica criado pelos produtores musicais Diplo e Switch.

15 William Grigahcine, é um produtor e DJ francês, conhecido por misturar hip hop e música eletrônica. 


\section{História da Comunicação 0 tempo: a lógica do ininterrupto}

A projeção conquistada após a música Open Bar, chamou atenção dos produtores da Rede Globo de Televisão. Em 2015 Vittar assumiu, no lugar de Leo Jaime ${ }^{16}$, o posto de vocalista da banda do programa Amor \& Sexo apresentado pela atriz Fernanda Lima (DANTAS, 2015). Sua primeira campanha publicitária veiculada na televisão ocorreu em 2016, quando participou do comercial 'Delegação \#Rio2016'17 da marca de cerveja Skol em comemoração aos jogos Olímpicos Rio 2016. Nesse período a artista ainda estava desenvolvendo o que seria o seu primeiro disco, além de permanecer como integrante do programa Amor \& Sexo.

O primeiro disco de estúdio 'Vai Passar Mal' lançado no início de 2017, foi produzido pela dupla Barbo Music ${ }^{18}$. O trabalho tem como particularidade a união de elementos da música pop internacional, com a sonoridade brasileira. Em entrevista ao jornal Correio Braziliense, Pabllo Vittar comentou que para essa brasilidade acontecer o processo de produção demorou um ano. As fotos usadas para compor a identidade visual foram feitas em uma fábrica desativada de manequins, Marlon Brambilla foi o fotografo, a escolha do local foi feita pensando nela enquanto performer (IZEL, 2017). Essa busca por trazer elementos da cultura brasileira, mais precisamente da cultura do Nordeste é uma marca característica em seu trabalho, tanto na música quanto na configuração imagética da sua Drag Queen.

A crítica especializada não poupou elogios a obra, ressaltando o conteúdo lírico das músicas que vão de encontro com o que seu público consome " em geral, suas faixas curtas e bem produzidas, com letras que exalam a autoestima e a afirmação de Pabllo, fazem do disco de estreia da drag queen um belo cartão de visitas - feito sob medida para o público que ela atinge”. (OLIVEIRA, 2017). Ainda em 2017, o vídeo da música Todo Dia se tornou o mais visualizado por uma Drag Queen na plataforma YouTube - levando em consideração 16 Leo Jaime é um cantor e compositor do gênero musical Rock, sua ascensão ocorreu durante a década de 1980. 17 Disponível em: $<$ https://www.youtube.com/watch?v=ZASvTD6JnBI\&feature=emb_title $>$. Acesso em: 5 set. 2020.

18 Brabo Music é uma dupla de produtores composta pelo ex-integrante da banda Bonde do Rolê Gorky e Maffalda, outro DJ brasileiro. A dupla é responsável por produzir diversas música de Pabllo Vittar, além disso Gorky atua como seu empresário. 


\section{História da Comunicação 0 tempo: a lógica do ininterrupto}

apenas músicas originais -, posto que era ocupado por RuPaul ${ }^{19}$, com o vídeo de 'Sissy That Walk' (NUNES, 2017).

Em agosto do mesmo ano, após o seu primeiro lançamento de forma independente, a Sony Music Entertainment Brasil e Vittar fecharam um contrato afim de produzir dois discos em parceria (CARMO, 2017). Sendo a primeira Drag a fazer parte do catálogo de artistas da gravadora no Brasil, um passo importante de sua trajetória. A participação no festival Rock In Rio 2017, no show da cantora Fergie ${ }^{20}$, foi outro momento de grande repercussão. A atuação no festival repercutiu em diversos portais de comunicação, sua popularidade só aumentou e diferentes marcas firmaram parcerias publicitárias com a cantora.

Transcendendo o sucesso de audiência nas redes sociais, em setembro de 2017 lançou o clipe para música "Corpo Sensual", nele todas as cotas de product placement liberadas foram adquiridas. A procura dessas marcas só reforçou o potencial mercadológico da artista, enxergado por essas instituições (SILVA, 2017). As marcas que anunciam no vídeo são: Trident, Avon, Absolut e o Ministério da Saúde, sendo essa a primeira ação em videoclipes do órgão federal.

Após o lançamento do seu segundo álbum de estúdio intitulado 'Não Para Não', a personagem criada por Phabullo Rodrigues da Silva começou a experimentar uma projeção fora do contexto brasileiro. Em 2018 a canção 'Sua Cara' do grupo Major Lazer com a sua participação, foi nomeada ao Grammy Latino ${ }^{21}$ na categoria Melhor Interpretação Urbana; um feito até então inédito para artistas da performance Drag. Em 2019 para apoiar a divulgação do segundo álbum de estúdio, Vittar saiu em turnê pelas principais paradas do Orgulho LGBTQ+ dos Estados Unidos e Canadá (ARAUJO, 2019). Concertos em festivais na América Latina e Europa também fizeram parte da agenda, assim como uma apresentação privada na sede da Organização das Nações Unidas.

19 RuPaul Andre Charles, conhecido como a Drag Queen RuPaul, tornou-se conhecido durante os 90 e atualmente comanda o reality show RuPaul's Drag Race. 20 Fergie Duhamel é uma cantora, rapper, apresentadora de TV, designer de moda e atriz estadunidense.

21 Disponível em:< https://www.grammy.com/grammys/news/brazilian-pop-star-pabllo-vittar-talks-new-album-111-and-life-musics-premier-drag-queen>. Acesso em: 29 jun. 2020.

Revista Tuiuti: Ciência e Cultura, v.7 n.62. p. 64-97, Curitiba, 2021 


\section{História da Comunicação 0 tempo: a lógica do ininterrupto}

Além do reconhecimento internacional através da música, o discurso e a imagem de resistência em prol dos direitos humanos de Pabllo Vittar foram reconhecidos por alguns meios de comunicação importantes. A revista inglesa Gay Times voltada para a comunidade LGBTQ+ de toda Europa, além de traze-la na capa da edição de abril de 2019, a definiu como "um farol de esperança para comunidade queer do Brasil” (MEGARRY, 2019). Ainda em 2019, a revista americana Time destacou que Vittar tem usado "sua plataforma como uma estrela musical para exigir igualdade para as comunidades LGBT no Brasil e fora dele" (CHOW, 2019). Esse afinamento do discurso político, começa a ser desenvolvido a partir da ascensão do conservadorismo no país com a eleição do presidente Jair Messias Bolsonaro em 2018.

Conclui-se que, por intermédio dos "rastros e restos" (BARBOSA, 2019, p. 7) da sua presença midiática, é possível elaborar uma historicidade da personagem vivida por Phabullo Rodrigues da Silva gerando sentidos de como sua expressão artística e seu discurso político, foram e são desenvolvidos. É nessa "estética do jogo e da bricolagem" (ROCHA; POSTINGUEL, 2017) que o fazer Drag, o menino maranhense emerge, misturando elementos da cultura nordestina com o que já é conhecido no cenário pop mundial. Essa parece ser sua "tática" (CERTEAU, 1946, p. 46), misturar o melhor dos dois mundos, quase como a antropofagia proposta por Oswald de Andrade. É o contexto brasileiro tão cruel para a comunidade LGBTQ+ que torna a presença de uma figura como Pabllo Vittar necessária, mesmo que seja apenas sua presença - o que como vimos, definitivamente, não é o caso.

\section{Referências}

ARAUJO, Guilherme. Pabllo Vittar vai se apresentar em 7 Paradas LGBTI+ nos EUA em turnê especial. Papelpop. 2019. Disponível em: < https://www.papelpop.com/2019/03/pabllovittar-vai-se-apresentar-em-7-paradas-lgbti-nos-eua-em-turne-especial/>. Acesso em: 07 ago. 


\section{História da Comunicação 0 tempo: a lógica do ininterrupto}

2020.

BARBOSA, Marialva Carlos. Comunicação e história: confluências. Interin, v. 24, n. 2, 2019.

Disponível em: <https://interin.utp.br/index.php/i/article/view/2142>. Acesso em: 03 set. 2020.

CHOW, Andre R. How This Brazilian Drag Queen Is Taking the Pop World By Storm - And Fighting for LGBTQ Rights Along the Way. Time (2019). Disponível em: <https:/ / time.com/collectionpost/5692972/pabllo-vittar-next-generation-leaders/>. Acesso em: 07 ago. 2020.

DANTAS, Felipe. Drag queen Pabllo Vittar irá comandar a banda do "Amor \& Sexo" no lugar de Léo Jaime. Papelpop (2015). Disponível em: <http://www.papelpop. com/2015/12/dragqueen-pabllo-vittar-ira-comandara-banda-do-amor-sexo-no-lugar-de-leo-jaime-2/>. Acesso em: 5 set. 2020.

DE CERTEAU, Michel. A invenção do cotidiano: 1. Artes de fazer, v. 16, 1994.

FERREIRA, Matheus. Os vencedores da Coca-Cola Fan Feat são Luan Santana, Simone e Simaria e Pabllo Vittar. Geek Publicitário (2018). Disponível em: < https://geekpublicitario. com.br/25685/vencedores-coca-cola-fan-feat/>. Acesso em: 2 abr. 2020.

IZEL, Adriana. Drag queen Pabllo Vittar lança primeiro disco da carreira, 'Vai passar mal'. Correio Braziliense. 2017. Disponível em: <https://www.correiobraziliense.com.br/app/ noticia/diversao-e-arte/2017/01/24/interna_diversao_arte,567603/pabblo-vittar-lanca-discovai-passar-mal.shtml>. Acesso em: 29 mar. 2020.

KOTLER, Phil; KELLER, Kevin L. Administração de Marketing. 14. ed. São Paulo: Pearson, 2012.

MARTINS, Sérgio. Diva de qualquer estação. Sucesso no You'Tube, nos palcos e no programa Amor \& Sexo, a drag queen Pabllo Vittar é a cantora mais animada da nova leva de artistas LGBT. VEJA, São Paulo, ed. 2535, ano 50, n. 25. 21 jun., p. 94-96. 2017.

MEGARRY, Daniel. Go behind the scenes on Pabllo Vittar's fierce GAY TIMES cover shoot. GAYTIMES. 2019. Disponível em: < https://www.gaytimes.co.uk/culture/go-behind-the- 


\section{História da Comunicação 0 tempo: a lógica do ininterrupto}

scenes-on-pabllo-vittars-fierce-gay-times-cover-shoot/>. Acesso em: 10 set. 2020.

NUNES, Gabriel. Pabllo Vittar é a drag queen com mais visualizações em clipe original no YouTube. Rolling Stone. 2017. Disponível em: < https://rollingstone.uol.com.br/noticia/ pabllo-vittar-e-drag-queen-com-mais-visualizacoes-em-clipe-original-no-youtube/ > . Acesso em: 3 set. 2020.

ROCHA, Rose Melo; POSTINGUEL, Danilo L. K.O: O nocaute remix da drag Pabllo Vittar. Revista E-Compoós, Brasília, v. 20, n. 3, p. 1-18, set. 2017. Disponível em: <http://www. ecompos.org.br/e-compos/article/viewFile/1416/951>. Acesso em: 29 mar. 2020.

SILVA , Damasceno. Pabllo Vittar exerce atração irresistível sobre as marcas: Clipe da cantora drag queen sai com todas as cotas de product placement vendidas. Disponível em: $<$ http:// www.meioemensagem.com.br/home/marketing/2017/09/08/pabllo-vittar-exerceatracaoirresistivel-sobre-as-marcas.html>. Acesso em: 27 mar. 2020.

\section{Práticas jornalísticas de inclusão e acessibilidade à informação: 0 uso da Língua de Sinais}

Elaine Polo Fortunato ${ }^{22}$

\section{0 surdo no Brasil e no mundo}

A história dos surdos é marcada pela exclusão. Na Idade Média, além de serem considerados estranhos e motivo de curiosidade para o resto da população, os surdos não recebiam tratamento. Para se ter uma ideia, até meados do século XV, o indivíduo surdo era considerado um amaldiçoado, uma pessoa castigada pelos deuses. De acordo com Veloso e Maia Filho

22 Mestranda em Comunicação e Linguagem - PPGCom-UTP 


\section{História da Comunicação 0 tempo: a lógica do ininterrupto}

(2009), só na Idade Moderna, a partir de aproximadamente 1453, foi que Bartollo Della Marca d'Ancora, um advogado, fez a primeira alusão de que o surdo poderia aprender, seja por uma língua de sinais. Alguns anos mais tarde, Girolamo Cardano concordou com o que d'Ancora considerou, que a surdez não impedia o desenvolvimento e aprendizagem. Mas somente em 1560, com a criação do livro Refugium infirmorum, do monge franciscano Yebra, é que a língua de sinais começou a ser difundida.

No Brasil, os primeiros passos para a educação de quem não ouvia começaram a ser dados em meados de 1855, por Eduard Huet. Huet era um professor surdo que chegou ao país com a aprovação do então imperador, Dom Pedro II. Ele veio para cá com o intuito de abrir uma escola para surdos, um público que até então era tido como ineducável no país. O professor fundou, no Rio de Janeiro, a primeira escola para surdos do país, o Instituto Nacional de Educação dos Surdos (INES), baseado nas doutrinas educacionais surdas da Europa.

Assim, a língua de sinais começava a ser difundida em nosso país, e devido às origens francesas de Huet, acabou sofrendo grande influência da língua de sinais da França. No Brasil, a Língua Brasileira dos Sinais (Libras), reconhecida como segunda língua oficial do país em 2002, é constituída pela combinação de forma e movimento das duas mãos, da expressão corporal e do espaço onde se realizam os sinais (Amaral; Souza, 2002, p. 381).

Hoje em dia, a necessidade de popularização da Libras tem relação com o panorama dos surdos no Brasil. De acordo com o IBGE, atualmente a população brasileira é constituída de aproximadamente 204 milhões de pessoas, das quais 5,1\% declaram ter deficiência auditiva e 2,1\% declaram ter deficiência auditiva grave.

Do mesmo modo, a situação dos surdos aparece nos meios de comunicação de massa. Levando-se em consideração que a televisão é o meio de comunicação mais utilizado atualmente e que $73 \%$ das pessoas assistem TV todos os dias, há mais de 10 milhões de pessoas surdas 


\section{História da Comunicação 0 tempo: a lógica do ininterrupto}

ou com algum tipo de surdez tentando assistir aos canais abertos de TV, que muitas vezes não disponibilizam nem closed caption6, nem janela de Libras.

Apesar do crescimento das novas tecnologias nos últimos anos, apenas $42 \%$ dos brasileiros utilizam a internet8. Nesse panorama, portanto, percebe-se uma carência de programas com acessibilidade ao público surdo. Mas como tornar um canal ou programa acessível?

Primeiramente, acessibilidade é a possibilidade e condição de alcance para utilização do meio físico, meios de comunicação, produtos e serviços, por pessoas com Os surdos (ABNT, 2004, p. 2). Diante dessa definição, um programa acessível é aquele que utiliza de recursos capazes de transmitir informação e entretenimento ao público com os surdos.

Existem quatro recursos principais que podem ser utilizados pelos canais para tornar sua programação acessível: o closed caption (legenda oculta); a janela de Libras; a dublagem e a áudio descrição de imagens, cada um com características específicas.

Como mencionado anteriormente, o closed caption é uma legenda oculta que aparece opcionalmente no televisor. Esse recurso - geralmente utilizado em programas de auditório, jornalísticos, esportivos, filmes, novelas, comerciais - pode ser pré-gravado ou oferecido ao vivo, durante o programa que está sendo exibido, ou seja, a legenda é produzida em tempo real, enquanto o programa está indo ao ar (ABNT NBR 15290, p. 2).

A configuração offline, ou pós-produzida, é a mais indicada, pois permite um tempo maior de produção, diminuindo o trabalho e aumentando a possibilidade de revisão do texto antes de ir ao ar. Para sua realização é necessário um programa de computador específico. O software transcreve não só o que está sendo dito, mas também as informações não-lineares, como ruídos, risos e aplausos, além da forma como cada fala está sendo dita. Esse recurso é utilizado em programas gravados, comerciais, filmes, novelas entre outros. 


\section{História da Comunicação 0 tempo: a lógica do ininterrupto}

Já a forma online ou em tempo real - também conhecida como legenda fechada -não segue um padrão de sincronismo com o que está sendo dito no programa. Por esse motivo, a legenda fechada não é a mais indicada, a não ser para os programas ao vivo. Essa legenda ainda pode ser produzida a partir de um estenótipo (teclado especial que representa letras e grupos de fonemas) ou de programas que reconhecem a voz e transcrevem o que está sendo dito para texto. Este recurso é utilizando em programas jornalísticos, esportivos, entre outros

Por sua vez, a janela de Libras é um espaço delimitado no vídeo, um recurso muito utilizado em propagandas eleitorais (ABNT NBR 15290: 3). Esse recurso disponibiliza um intérprete que fica traduzindo o que está sendo dito para a Libras. Além disso, de acordo com a ABNT NBR 15290/2005, o local da gravação deve ter espaço suficiente para que o intérprete não fique no fundo, e tenha um espaço de movimentação delimitado para não correr o risco da mão de quem estiver librando "vaze" do quadro.

Já o recurso da dublagem faz uma tradução de um produto que originalmente está em outra língua. (ABNT NBR 15290: 2). Por último, a áudio descrição de imagens funciona com a narração de sons, elementos visuais, gestos e peças de vestuário que aparecem na tela (ABNT NBR 15290: 2). Todos esses recursos estão disponíveis de acordo com e legislação brasileira.

Embora exista a regulamentação e a diversidade da programação televisiva, o alcance do público surdo ainda é ineficiente, pois os recursos previstos por lei são pouco ofertados. Devido a isso, parte desse público não tem acesso ao conteúdo audiovisual completo, ficando impossibilitado de receber de forma total as informações que estão sendo transmitida pelo veículo.

O curioso é que graças aos recursos tecnológicos atuais, os métodos de acessibilidade não exigem grandes dificuldades para serem aplicados, principalmente com a TV Digital. 


\section{História da Comunicação 0 tempo: a lógica do ininterrupto}

Torres e Mazzoni (2007) consideram que a boa utilização dos recursos de acessibilidade nos canais brasileiros de TV aberta permitiria que o público que não pode ter um pleno aproveitamento dos recursos audiovisuais utilizados na televisão conseguisse receber a informação transmitida de forma satisfatória.

Pensando nisso, é importante aprofundar a discussão a respeito do uso das ferramentas de acessibilidade e de suas vantagens comunicativas, especialmente no que se refere ao telejornalismo.

\section{Conclusão}

Com bases nas ideias de Gesser (2014), entende-se que é necessário falar as pessoas sobre o universo dos surdos, pois pouco ainda se sabe sobre isso. A autora defende a relevância de passar adiante informações sobre a Língua brasileiras de sinais, reconhecida pelo governo brasileiro e por acadêmicos como modo mais eficaz para desenvolvimento e comunicação do surdo.

Nesse processo, a mídia é essencial, uma vez que pode ajudar na conscientização e combate às injustiças sociais. Além disso, através da tecnologia, muito se avançar em questões sobre acessibilidade e mídias acessíveis.

Este artigo se baseou na perspectiva de que, embora considerado minoria, o surdo também tem direito à informação. Para que o artigo da Constituição Brasileira que prevê o direito de todos à informação seja cumprido, faz-se necessário a utilização de recursos que incluam o surdo como receptor da mensagem, pensando-se tanto nos surdos que sabem o português, e podem ler as legendas, como naqueles que não sabem, e requerem a presença de um intérprete de Libras. Mais ainda, a representação da comunidade surda se dá também pela representação dessa parcela de público nas matérias telejornalísticas. 


\section{História da Comunicação 0 tempo: a lógica do ininterrupto}

\section{Referências}

AMARAL, S. T.; SOUZA, M.C. O direito de ouvir com os olhos nas TVs brasileiras de sinal aberto. Revista Intertemas. São Paulo: Vol 12, p.357-386. Disponível em: http://intertemas. unitoledo.br/revista/index.php/INTERTEMAS/article/viewFile/740/739

>. Acesso em: 31/08/2015.

CALEGARI, G.H. A sonorização como produtora de sentido no telejornalismo esportivo do esporte espetacular. Porto Alegre, 2012. Disponível em: <https://www.lume.ufrgs.br/bitstream/ handle/10183/67257/000871829.pdf? sequence=>. Acesso em: 17/11/2015.

Brasil Lei. Lei 10.436, da oficialização da Língua Brasileira de Sinais - Libras 2000.

LOPES, M. C. Surdez \& Educação. Belo Horizonte: Autêntica: 2007.

MOURA, Maria Cecília. Surdo: caminhos para uma nova identidade. Ed. Revinter.

QUADROS, R. M. de; KARNOPP, L. B. Língua de sinais brasileira: estudos linguísticos. Porto Alegre: ARTMED, 2004.

SILVEIRA, C.H. Representação de surdos/as matérias de jornais e revistas brasileiras. Revista Centro de educação. Santa Maria, 2008, Vol 33, n 01. Disponível em: < http:/ / coralx.ufsm.br/ revce/revce/2008/01/a11.htm>. Acesso em: 16:11/2015.

SOUZA, S.X. Sentidos do outro lado: Percepção da mensagem de notícias do telejornal local de TV aberta. "Jornal do 10” por sujeitos surdos. Arara Azul. Rio de Janeiro, 008 Vol 02. Disponível em: < http://www.editora-arara-azul.com.br/revista/02/compar2.php>. Acesso em: $1 / 10 / 2015$.

SKLIAR, Carlos. La educación de los sordos. Una reconstrucción histórica, cognitiva y pedagógica. Mendoza: Editora Universal de Cuyo, Serie Manuales, 1997. 


\section{História da Comunicação 0 tempo: a lógica do ininterrupto}

\section{Uma perspectiva histórica sobre o corpo na umbanda}

\section{Maurício Ferreira Santana ${ }^{23}$}

Quando imaginamos o corpo em seu aspecto material, corpo humano estésico, místico ou sexual e funcional, pressupomos que ele faça parte de um sistema cultural, de uma sociedade ou território. Cada corpo material, em alusão a Gilles Deleuze, possui sua individualidade, mas ao mesmo tempo caracteriza-se tanto por suas idiossincrasias como pela identidade de grupo, herdada pelo costume ou pela tradição. Com essas premissas em mente, adotamos a concepção de Eric Hobsbawn e Homi K. Bhabha - em suas reflexões sobre a invenção da tradição - com a complexidade de um conjunto de corpos, um "corpo coletivo" que herda (ou mesmo inventa) suas próprias tradições, bem como as perpetuam dentro de um sistema cultural composto pelos elementos propostos por Benedict Anderson - a territorialidade, a soberania - na formação de uma comunidade imaginada.

Além disso, podemos supor que o corpo em movimento compõe uma narrativa: o corpo também é ação, enquanto o corpo estanque é o espelho da ausência da vida. Narrativa de vivência, de relacionamentos e interconexões, o corpo tal qual o conhecíamos até pouco tempo - um corpo material identitário que começa a fragmentar-se no século XIX e promiscuir-se no século XX acaba por liquefazer-se em nosso século, como vaticinaram Stuart Hall e Zygmunt Bauman. E é em nosso século XXI que a materialidade do corpo encontra sua crise existencial como componente de uma ação narrativa de pertencimento a um espaço também material.

O corpo receptáculo do mistério, do sagrado, do oculto - e aqui não aludimos ao "corpo de Cristo" materializado na hóstia, e sim ao corpo nas religiões de matriz africana, em especial a

23 Doutorando em Comunicação e Linguagens pela Universidade Tuiuti do Paraná.jose_sandino@yahoo.com.br 


\section{História da Comunicação 0 tempo: a lógica do ininterrupto}

Umbanda - é o meio de expressão do que vem do Orun (o céu sagrado na língua iorubá), ou seja é o médium, o que está entre as duas partes, Orun e Aiyê (a terra). E para que o médium medie o que vem do Orun aos filhos da terra, é necessário estar no centro do mundo, no espaço sagrado, na terra - daí que denominamos terreiro - espaço onde ocorre a conexão; muito mais do que uma epifania, para Mircea Eliade transborda a hierofania, o ponto máximo da experiência religiosa.

Religiões praticadas no Brasil que tem matriz africana em sua totalidade ou em parte de sua composição, de forma direta (candomblés e umbandas ${ }^{24}$, tambor de mina, entre outras menos populares) e indireta (Jurema, que tem matriz fortemente de origem indígena, porém possui em seu panteão de entidades, por exemplo, Zé Pelintra, que também transita nas umbandas, ora como mestre juremeiro, ora como malandro carioca) são religiões de prática corporal, a qual, segundo Sodré (2006), tem importância ímpar na experiência do sagrado:

$\mathrm{Na}$ cosmovisão desses cultos [...] colocam-se em primeiro plano o reconhecimento do aqui e agora da existência, as relações interpessoais concretas, a experiência simbólica do mundo, o poder afetivo das palavras e ações, a potência de realização das coisas e a alegria frente ao real [...da] experiência do sagrado em sua radicalidade. Decorre daí a grande importância outorgada ao corpo. (SODRÉ, 2006, p, 210).

O corpo negro trazido da África para o Brasil como força escravizada era então considerado "sem alma" pelos colonizadores portugueses, como ilustra Bastide (1985): "[...] os senhores ou proprietários de escravos não estavam interessados em suas almas e sim em seus corpos. Não viam neles seres a salvar e sim máquinas de trabalhar." (BASTIDE, 1985, p. 182). A partir disso formaram-se dois "corpos coletivos" negros: um, aglutinado e voltado ao trabalho escravo, sem

24 Nos referimos a"candomblés" e "umbandas" porque não são religiões de uma única orientação canônica, como a religião católica, por exemplo - mesmo porque elas não possuem cânones, sendo essencialmente religiões baseadas na tradição oral. 0 Candomblé possui diversas vertentes, fundamentos e práticas de acordo com seu reino ou nação africana (Jeje, Nagô, etc.), bem como a Umbanda, que possui diversas vertentes (Umbanda Branca, Popular, Sagrada, Esotérica, Traçada, entre outras). 


\section{História da Comunicação 0 tempo: a lógica do ininterrupto}

identidade - e sem alma -; outro, remendado e fragmentado (porém sagrado), sincretizado tanto no cânone católico quanto nas semelhanças e diferenças dos cultos de diferentes reinos africanos.

E é justamente esse corpo sagrado e fragmentado que recebeu atenção à guisa de um estudo etnográfico por João do Rio no início do século XX, onde o autor retrata o amálgama existente na então capital federal das diferentes práticas religiosas, tanto de matriz africana quanto de influências europeias; particularmente nos chama a atenção a diversidade de denominações e sincretismos de cultos que hoje não mais existem - mas que tinham em comum essa associação corpo / espaço sagrado e também elementos como a dança e o ritmo da percussão:

A dansa [sic] dessas cerimonias é mais ou menos precipitada, mas sem os pulos satânicos dos Cafres e a vertigem diabólica dos negros da Luiziania. E' simples, continua e insistente, horrendamente insistente. Os passos constantes são o alujá, em roda da casa, dando com as mãos para a direita e para a esquerda, e o jêguedê, em que ao compasso dos atabaques, com os pés juntos, os corpos se quebram aos poucos em remexidos sinistros. (RIO, 1906, p. 21).

Observamos que a partir dos estudos de Leal de Souza - os quais consideramos também como registros etnográficos - iniciados nos anos 1920, temos os primeiros registros escritos e publicados onde efetivamente se menciona a "Umbanda", inclusive denominando-a como religião.

A incorporação é sempre um fenômeno complexo, que se processa mediante acidente psicológico, físico e espiritual, e tem na Linha Branca de Umbanda a expressão máxima de sua transcendência. Vulgarmente, basta que o espírito se assenhoreie dos órgãos cerebrais, vocais, e manuais, ou de todos os chamados nobres, para fazer a comunicação

verbal ou escrita, e dar passes. Na Linha Branca, precisa apropriar-se de todo o organismo do médium, porque nesse corpo vai viver materialmente algumas horas, movendo-se, 


\section{História da Comunicação 0 tempo: a lógica do ininterrupto}

utilizando-se de objetos, às vezes suportando pesos. A incorporação na Linha Branca é quase uma reencarnação, no dizer de um espírito. (SOUZA, 1933, p. 44-45).

Outro aspecto que também merece menção nos escritos do autor, quando falamos do corpo, é a prática da incorporação, a qual é a chave para a experiência traduzida como hierofania. A incorporação, o tomar um corpo, uma forma material, é também retratada por Pierre Verger, subsequentemente como uma encarnação: "[...] durante as cerimônias realizadas em seu louvor apressam-se em volta as terras, encarnando-se nos corpos em transe de seus descendentes que lhes são consagrados." (VERGER, 2018).

Através desse parcimonioso apanhado histórico buscamos chegar até onde é possível no plano da materialização da experiência religiosa, a hierofania tangível; a partir dessa compreensão temos mais perguntas que respostas, mais inconclusões que desfechos; pretendemos nos voltar para a ausência do corpo na liturgia umbandista, como um devir que leva a um outro território, o território virtual: haverá uma ruptura em relação a essa milenar narrativa corpórea, desgarrada dos seus "centros" do mundo - os terreiros, espaços sagrados -, os quais passam a ser endereçados com "www", e cujos médiuns liquefazem-se em bits e bytes? Precisamos tensionar a relação do corpo e do espaço físico transportados para uma dimensão intangível, e investigar se ainda será possível que as forças do Orun possam se manifestar na egrégora do Aiyê, e de que forma a incorporação - e consequentemente a encarnação - atravesse essa mudança para que ainda ocorra a celebração do sagrado.

\section{Referências}

BASTIDE, Roger. As religiões africanas no Brasil: contribuição a uma sociologia das interpenetrações de civilizações. 3. ed. São Paulo: Pioneira, 1985. 


\section{História da Comunicação 0 tempo: a lógica do ininterrupto}

RIO, João do. As religiões no Rio. Rio de Janeiro: Paris: H. Garnier, 1906.

SOUZA, Leal de. O espiritismo, a magia e as sete linhas de Umbanda. Rio de Janeiro: [s. n.], 1933.

VERGER, Pierre Fatumbi. Orixás: deuses iorubás na África e no Novo Mundo [livro eletrônico]. 2018[?]. Disponível em: <https://docero.com.br/doc/x5x0x>. Acesso em: 10 jan. 2020.

\section{Nota}

Essa nota é complementar aos três primeiros parágrafos desse ensaio: Gilles Deleuze alude à fábrica que constitui os indivíduos como um único corpo, em seu "Post Scriptum sobre as sociedades de controle”, teorizadas por Foucault; a ideia de invenção das tradições consta em Hobsbawn (na obra homônima) e em Bhabha em seu livro "O local da cultura"; comunidades imaginadas em Anderson estão na obra homônima. A noção de identidade fragmentada aparece na obra de Hall "A identidade cultural na pós-modernidade" e as identidades líquidas de Bauman na obra "Modernidade líquida"; hierofania e espaço sagrado estão em "O sagrado e o profano" de Mircea Eliade.

\section{Breve historiografia de uma tese de comunicação}

Ricardo Uhry ${ }^{25}$

A rica vivência dos dois primeiros setênios da vida, que corresponde à passagem dos treze anos aos quatorze anos, que, no caso, aconteceu em 1970, é uma época de rituais e também pode

25 Doutorando em Comunicação e Linguagem PPGCom-UTP 


\section{História da Comunicação 0 tempo: a lógica do ininterrupto}

ser considerada a base em que se desenvolve o imaginário, que é, por um lado, um período muito voltado à imaginação e, por outro, ao que se imagina ou quer ser no futuro, além de que tem a influência das leituras e do vivido, o que, examinado cinquenta anos depois, são lembranças históricas pessoais relacionadas ao imaginário (SILVA, 2012 e 2017) e à construção de uma mitologia pessoal (FEINSTEIN; KRIPPNER, 1997), e dão motivo a um início de um "fazer historiográfico" (BARBOSA, 2013, p. 5) de uma tese de comunicação.

A abordagem metodológica deste pequeno ensaio tem por objeto "casos individuais" (GINZBURG, 2007, p. 158) e aproxima-se de um estudo de caso único (YIN, 2001, p. 61-67). Foca uma historiografia de uma tese, para o que se utiliza técnicas de pesquisa indiciária (BRAGA, 2008; GINZBURG, 2007). A propósito, Ginzburg (2007) cita a historiografia como relacionada à "história dos homens", destacando-a como "uma investigação sem preconceitos", além de que também registra: “o conhecimento histórico é indireto, indiciário, conjetural” (GINZBURG, 2007, p. 155-157).

No caso historiográfico em particular, em 1970 é que se começa definir imaginativamente o que se quer ser no futuro. Nessa época foi marcante o ritual de confirmação da fé que ajudou a compor meu imaginário cristão e pode-se dizer que teve tamanho impacto em minha vida que até pensei em me tornar pastor luterano, o que entusiasmou minha mãe, mas não agradou meu pai e seu melhor amigo, meu padrinho Dr. Guido. Sobre as "convenções de um tempo", Silva (2017, p. 131) esclarece: "Nada, porém, impede que se dê a revisão do conteúdo primeiro" que, na história vivida, é o imaginário de me tornar pastor.

Com base em Feinstein e Krippner (1997, p. 29-52), aos 14 anos eu teria construído um mito pessoal de pastor, pois em minha família houve um tataravô (pelo lado materno) que foi pastor. Em meu imaginário persistia a imagem do ancestral cercado de confirmandos, mas talvez me perderia: "Onde existe um caminho ou trilha, existem as pegadas de outrem. Cada um de nós tem de encontrar o próprio caminho...” (FEINSTEIN; KRIPPNER, 1997, p. 42). 


\section{História da Comunicação 0 tempo: a lógica do ininterrupto}

Uma das instituições mais relevantes para a construção da mitologia pessoal, na época, ao lado da igreja, era a escola. Em 1970 cursava a segunda série do ginásio industrial: pela manhã tinha aulas normais e, à tarde, eletricidade nas oficinas. A escola me proporcionou oportunidade de "como reconhecer um mito-guia", de acordo com Feinstein e Krippner (1997, p. 53-78), ou seja, mobilizar meu novo mito pessoal: o imaginário de professor.

Também foi em 1970 que comecei a escrever o relato de "Jor, o observador", uma espécie de herói que concebi, por influência das leituras, datilografando em uma máquina de escrever Olivetti Linea88, que era de meu pai. É meu escrito mais antigo que guardei daquele tempo, algo a propósito do que Feinstein e Krippner (1997, p. 56) registram: "E você pode recordar experiências da infância com uma sensação irreal de alegria, segurança ou encanto", pois se trata de seu "ritual pessoal" na forma de um paraíso perdido.

Em minha imaginação, de quase pastor luterano, acabei quase professor e, finalmente, escritor observador, o que tem a ver com jornalismo: logo a seguir, em 1972, passei a escrever crônicas em jornais, editei um pasquim (O Fiasquim), cheguei a ter um conto premiado publicado em revista de circulação nacional, trabalhei em jornal (A Tribuna), fiz Letras (1975-1979), fui professor (Línguas portuguesa e inglesa) e trabalhei como redator de rádio (Cultura)...

Até finalmente me tornar bancário em 1977, uma longa jornada de 29 anos, apesar de ter continuado paralelamente professor e escritor. Fiz jornais alternativos (Pholha, Bop, Rascunho, Pirata News) e, em 1982, tornei-me professor instrutor de comunicação e expressão no banco. Em 1997, quando o banco criou uma universidade corporativa, tornei-me "instrutor residente", professor com dedicação exclusiva, o que perdurou até 1999, quando ingressei no mestrado.

Assim, a partir de um marco histórico inicial (1970), trinta anos depois (2000), bancário e escritor, cursava o mestrado em Administração na Universidade Federal do Paraná (UFPR) e pesquisava estratégias de gestão da informação e do conhecimento. Na ocasião, meu orientador, 


\section{História da Comunicação 0 tempo: a lógica do ininterrupto}

professor doutor Sergio Bulgacov, pediu-me indicações bibliográficas sobre comunicação. Ao fazer o levantamento, fiquei revendo minha literatura na área e refletindo sobre comunicação.

Ao concluir o mestrado, em 2001, assumi maiores responsabilidades profissionais, o que incluiu a diretoria de comunicação da fundação do banco. Sempre lecionando (Língua portuguesa instrumental, Comunicação administrativa e outras), iniciei minhas pesquisas de comunicação interativa, focando as competências básicas da comunicação, o que resultou na publicação de uma obra pela Editora da UFPR em 2010. Pouco antes publiquei meu primeiro livro de ficção (2008), ao que se seguiram mais dois livros ficcionais em 2018.

Continuei minhas buscas, pesquisando a comunicação com a sociedade e quando vi estava com uma obra de 420 páginas, a qual enviei a uma editora acadêmica. Três pareceristas comentaram e dois deles sugeriram que dividisse o livro em dois volumes, além de fazer interessantes sugestões. Estou com o desafio de rever o trabalho.

Ao ver meu empenho, minha esposa falou, "por que você não faz doutorado? Irá facilitar com suas pesquisas". Ela tem razão! Pensei também que teria um interlocutor para orientar e ajudar-me a me tornar um pesquisador que possa trazer uma contribuição.

Era final de 2019. Estudei as possibilidades existentes e vi que estava aberta a concorrência para o doutorado em Comunicação e Linguagens da Universidade Tuiuti do Paraná, nível 5 na Capes. Candidatei-me e, em 2020, eis-me iniciando uma nova caminhada, a do doutorado.

Apresentação do tema do doutorado: práticas inovadoras de comunicação digital vêm apresentando uma combinação de tecnologia e de criatividade, da qual se destaca participação, experimentação, sensibilização e estética. Com um estudo de caso sobre tais práticas comunicacionais, busca-se produzir conhecimento em que o problema não é simplesmente o digital em si, ou os comunicadores/internautas/leitores, mas envolve as perspectivas Social, 


\section{História da Comunicação 0 tempo: a lógica do ininterrupto}

Mercadológica, Comunicadores e Públicos das práticas a serem analisadas e das relações que se formam. Justificativa: na linha de pesquisa "Processos mediáticos e práticas comunicacionais" constam as "relações intersubjetivas", que são mediadas de "diferentes formas", o que inclui o digital, e também que "investiga práticas comunicativas em suas configurações", o que está na proposta de identificar e refletir criticamente sobre práticas inovativas da comunicação digital. O grupo de pesquisas é INCOM Interações comunicacionais, imagens e culturas digitais que tem digitais em sua essência. Problema: Práticas inovadoras de comunicação digital podem ser relacionadas com participação, experimentação, sensibilização e estética? O objetivo geral é delinear as relações comunicativas e, em especial, as práticas inovadoras digitais. Operadores teóricos: práticas inovadoras, comunicação digital, participação, experimentação, sensibilização, estética.

Em suma, começamos o passeio historiográfico com a "recuperação rotineira dos fatos do passado" (BARBOSA, 2019, p. 6): as lembranças de 1970 do imaginário de um jovem (pastor, professor, jornalista), o relato de um garoto de 14 anos (Jor, o observador) e sua posterior vida acadêmica (1975-1979; 1999-2001) e profissional (1972, 1975, 1977-2016). Que é algo que pode ser relacionado ao imaginário do jornalismo, que seria o que "Jor" de forma amadora estava tentando fazer em 1970, ao registrar a percepção (o vivido), como se fora jornalista, uma espécie de "historiador do instante" (BARBOSA, 2019, p. 5), como ensinou Camus.

Chegamos assim a uma história vivida que ajudou a compor uma breve historiografia desde 1970 (imaginário, história vivida), sugerindo-se um entrelaçamento entre as buscas por saberes (graduação 1975, mestrado 2000, doutorado 2020) com os caminhos da comunicação [observador “Jor”, jornalista, escritor (2008, 2010, 2018), diretor de comunicação] que desencadearão em uma tese. 


\section{História da Comunicação 0 tempo: a lógica do ininterrupto}

\section{Referências}

BARBOSA, M. C. Comunicação e história: confluências. Interin, v. 24, n. 2, jul./dez. 2019, p. 4-20.

BRAGA, José Luiz. Comunicação, disciplina indiciária. MATRIZes, n. 2, abril 2008, p. 74-88.

FEINSTEIN, D.; KRUPPNER, S. Mitologia pessoal. São Paulo: Cultrix, 1997.

GINZBURG. Carlo. Sinais: raízes de um paradigma indiciário. In: . Mitos, emblemas, sinais.

São Paulo: Companhia das Letras, 2007, p. 143-179.

SILVA, J. M. Diferença e descobrimento: o que é o imaginário? (A hipótese do excedente da significação). Porto Alegre: Sulina, 2017. . As tecnologias do imaginário. $3^{\text {a }}$. ed. Porto Alegre: Sulina, 2012.

YIN, Robert K. Estudo de caso: planejamento e métodos. Porto Alegre: Bookman, 2001.

\section{Reflexões sobre as fronteiras entre liberdade de expressão e preconceito: o caso do especial de Natal do Porta dos Fundos}

Vitor Emanuel Pinto Cardoso ${ }^{26}$

\section{Introdução}

A Liberdade é um elemento intrínseco ao crescimento do ser humano como pessoa, nos permite explorar o mundo e interpretá-lo a nossa maneira, no entanto ela se restringe quando estamos em sociedade, definições daquilo que se chama liberdade são dependentes dos contexto social de cada grupo, assim quando duas sociedades se encontram tais definições podem gerar conflitos sendo

26 Mestrando em Comunicação e Linguagem PPGCom-UTP 


\section{História da Comunicação 0 tempo: a lógica do ininterrupto}

uma manifestação recorrente o preconceito (CARDOSO, 2019). Nesse contexto o objetivo deste trabalho é discutir sobre os limites da liberdade de expressão e preconceito através de um estudo de caso do Especial de Natal de 2019 do site Porta dos Fundos. A metodologia de estudo será qualitativa descritiva pois analisará a visão da Porta dos Fundos com as da sociedade brasileira. Serão artigos relacionados a liberdade de expressão, o conceito da laicidade na sociedade brasileira e notícias sobre a história da Porta dos Fundos e seu histórico.

\section{Contextualização: a história do Porta dos Fundos}

Em 2011 Fabio Porchat e Ian SBF, fundadores do canal de Youtube Anões em Chamas, junto aos atores Antônio Tabet e Gregório Duvivier e o publicitário João Vicente de Castro, fundaram a produtora "Porta dos Fundos". Inicialmente, o projeto foi de fato proposto a canais de tv, mas isso foi abandonado em parte de encontrar um canal que estivesse disposto e ainda pelo próprio proposito do projeto. Sua primeira produção, ainda em fase de testes e antes do formato atual, foi a serie parodia CSI Nova Iguaçu, no entanto em pouco tempo o formato de vídeos sem conexão cronológica foi estabelecido (PINHEIRO, 2013). Para divulgar seu primeiro episódio os produtores utilizaram não apenas as redes sociais, mas a própria influência, como Tabet que usou seu site "Kibe Loco" e o uso de outros sites de humor. Essa estratégia levou mais pessoas a assistirem o vídeo fora do que no Youtube (GOOGLE, 2014). Trinta e sete das enquetes da produtora foram mais tarde compiladas em um livro publicado em 2013, permitindo assim alcançar outras mídias e contendo as reflexões dos autores sobre suas produções. No livro Porta dos Fundos um breve texto descreve o grupo:

PORTA DOS FUNDOS é um coletivo criativo criado por amigos e para amigos. Simples assim. A ideia de sair da TV e migrar para uma mídia na qual seríamos nossos próprios 


\section{História da Comunicação 0 tempo: a lógica do ininterrupto}

editores, chefes e velhinhos que censuram baseados na moral e nos bons costumes - que pregam, mas não colocam em prática - parecia bastante atraente e promissora. E foi. (PORTA DOS FUNDOS, p. 09, 2013 apud DA SILVEIRA, 2016)

Mesmo em seu início os produtores já admitiam as controvérsias e conflitos acerca de seus trabalhos, como dito na introdução do mesmo livro:

Quando alguém não gosta de um vídeo e diz que vai nos processar, a gente tem a consciência tranquila. Lembramos das reuniões intermináveis e de como foi difícil chegar àquele texto do vídeo. Quem não gosta só pode ser uma pessoa muito sozinha que está querendo atenção (ou rola). (PORTA DOS FUNDOS, p. 10, 2013 apud DA SILVEIRA, 2016)

Ou seja, o objetivo do "Porta dos Fundos" em seu próprio título propõe um humor satírico e ácido para conteúdo de intenção provocativa e sem restrições, trabalhando como uma porta para o fundo da produção humorística e de conteúdo brasileiro gerando produções sem se literal porta para os fundos do humor brasileiro (PINHEIRO, 2013). Em 3 de dezembro de 2019 estreia o Especial de Natal do Porta do Fundos: A Primeira Tentação de Cristo direto para a Netflix. O especial satiriza o retorno de Cristo após 40 dias no deserto ao revelar que ele volta com um amante, ou seja, tendo uma relação homossexual, para o choque de sua família e mesmo de Deus (DA REDAÇÃO, 2019). Esse conteúdo logo gerou críticas e ameaças de boicote a Netflix. Principalmente da Coalizão pelo Evangelho grupo que tem por membro o deputado Marco Feliciano. Em artigo publicado no site da Coalizão o pastor da Igreja Presbiteriana do Bairro Imperial no Rio de Janeiro, Joel Theodoro explica que cancelou sua assinatura: 


\title{
História da Comunicação 0 tempo: a lógica do ininterrupto
}

\begin{abstract}
Manter-me na qualidade de um patrocinador de produções cinematográficas que zombam e vilipendiam o Senhor é o mesmo que esbofeteá-lo, cuspir nele, bater em sua cabeça para lhe enterrar os espinhos da coroa, zombar com deboches, forçá-lo a andar nu pelas ruas carregando o grande peso do madeiro, furá-lo ao lado com uma lança, gritar para que ele desça da cruz se for capaz. (THEODORO, 2019 apud DA REDAÇÃO, 2019).
\end{abstract}

Marco Feliciano também se manifestou no twitter:

Cristãos e não cristãos me cobram atuação contra os irresponsáveis do Porta dos Fundos. Em anos anteriores já os processei, mas a "Justiça" diz q é liberdade de expressão. Está na hora de uma ação conjunta das igrejas e pessoas de bem para dar um basta nisso. Unidos somos fortes! (DA REDAÇÃO, 2019).

As controvérsias tiveram seu ápice quando em 24 de dezembro de 2019, ou seja, véspera de natal, quatro pessoas atacaram a sede da produtora com bombas incendiarias, ninguém foi ferido (REDAÇÃO, 2019). Um dia depois um vídeo divulgado no Youtube apresentava supostos integralistas mascarados admitindo a autoria do atentado e se identificando como sendo do Comando de Insurgência Popular Nacionalista da Grande Família Integralista Brasileira (BBC NEWS, 2019), mais a tarde a verdadeira Frente Integralista Brasileira (FIB) negou participação no ataque e autoria do vídeo, chegando mesmo a expulsar um de seus membros suspeito de participar do ataque (HERDY, 2019).

\section{O humor na Filosofia}

O humor tem como um dos seus primórdios a antiga Grécia, um exemplo importante a este texto está no mito de Demeter quando sua escrava, Iambe, tenta animar a ama que 


\section{História da Comunicação 0 tempo: a lógica do ininterrupto}

estava depressiva sem comer ou beber: "antes com zombaria Iambe, diligente, fazendo muitas brincadeiras, deixou a senhora sagrada alegre e com ânimo, ao rir e se regozijar (HINO HOMÉRICO A DEMÉTER, vv. 202-204 apud DRUMMOND, 2012)

Esse trecho está um dos primeiros usos da aiskrologia, isto é, elementos linguísticos que incluem o obsceno (O’HIGGINS, 2003 apud DRUMMOND, 2012). Segundo Rackford (1987, p.461 apud DRUMMOND, 2012) o humor teria então a combinação da aiskrologia com a criatividade pessoal como elementos centrais. Nesse sentido também pode se observar que nos polos do humor mais refinado aos chistes mais grosseiros é necessário considerar o contexto político-social para se criar uma real conexão e o cômico atinja seu objetivo (DRUMMOND, 2012).

Nesse contexto é interessante notar que as antigas peças humorísticas gregas já possuíam um conteúdo satírico contra as posturas de hipocrisia dos cidadãos das cidades, o objetivo seria para Aristóteles um processo catártico para o público, um meio para essas pessoas refletirem em suas próprias faltas e erros através de sátiras de humor ácido e provocante (PINHEIRO, 2019 e DRUMMOND, 2012).

Para Platão o humor necessita de uma mescla entre dor e prazer, sendo o riso também nascidos de zombar do ridículo dos outros, ou seja, de se colocar em posição superior ao outro (DRUMMOND, 2012). Isso significa que a comedia e tragédia nasceram da mesma fonte no contexto dramático teatral e que o humor já era satírico em sua origem (DRUMMOND, 2012). De fato, a filosofia grega em si também tinha como um dos objetivos a provocação do outro, uma abordagem crítica do status quo político, social e moral da época. Portanto muitos filósofos fora da Grécia terminavam perseguidos e mortos devido a suas polêmicas ideologias e discursos (PASSOS, 2008). 


\section{História da Comunicação 0 tempo: a lógica do ininterrupto}

\section{Conclusão}

A discussão deste texto não procurou explicar seu questionamento principal: quais são os limites da liberdade de expressão. Pois é uma discussão de cunho subjetivo e controverso, procuramos sim exemplificar a temática através do caso do Especial de Natal do Porta dos Fundos. Na democracia devemos ter atenção tanto a restrição da liberdade quanto a seu abuso, a liberdade não existe sem limites, mas sua delimitação termina por ser complexa e controversa, mesmo assim não devemos abrir mão da liberdade, mas construir uma dialogia, um equilíbrio nascido da diferença.

\section{Referências}

BBC NEWS. Brazil police investigate fire-bombing of 'gay Jesus' film office. BBC News, 2019.

Disponível em: https://www.bbc.com/news/world-latin-america-50918636. Acesso em $01 / 11 / 2020$

CARDOSO, Vitor Emanuel Pinto. REFLEXÕES SOBRE AS FRONTEIRAS ENTRE LIBERDADE DE EXPRESSÃO E PRECONCEITO: O CASO DAS CHARGES DE CHARLIE HEBDO.. In: Anais do VI Fórum Brasileiro de Pós Graduação em Ciência Política. Anais...Belém(PA) UFPA, 2019. Disponível em: <https//www.even3.com.br/ anais/vifbcp/150704-REFLEXOES-SOBRE-AS FRONTEIRAS-ENTRE-LIBERDADEDE-EXPRESSAO-E-PRECONCEITO_O CASO-DAS-CHARGES-DE-CHARLIEHEBDO>. Acesso em: 02/11/2020

DA REDAÇÃO. Porta dos Fundos: especial de Natal da Netflix revolta grupos religiosos. Revista Veja, 2019. Disponível em: https://veja.abril.com.br/religiao/porta-dos-fundos-especial-denatal-revolta-grupos-religiosos/. Acesso em 01/11/2020

DA SILVEIRA, André Luiz. A Soleira da Porta dos Fundos: A Brecha como ponto de partida para a criação humorística. TEOLITERARIA-Revista de Literaturas e Teologias, v. 6, n. 11, p. 313-330, 2016. 


\section{História da Comunicação \\ 0 tempo: a lógica do ininterrupto}

DRUMOND, Greice. As formas do riso na comédia grega antiga. Niterói: Universidade Federal Fluminense, 2012.

GOOGLE. HISTÓRIA DOS CRIADORES DO YOUTUBE: Como Porta dos Fundos roubou a cena e se tornou o canal com mais inscritos do Brasil. Google Think Storage, 2014. Disponível em: https://think.storage.googleapis.com/intl/ALL_br/docs/porta-dos-fundosyoutube-brasil_case-studies.pdf. Acesso em 01/11/2020

HERDY, Thiago. Frente Integralista Brasileira nega relação com grupo que assumiu atentado à sede do Porta dos Fundos. O Globo, 2019. Disponível em: https://oglobo.globo.com/rio/ frente-integralista-brasileira-nega-relacao-com-grupo-que-assumiu-atentado-sede-do-portados-fundos-24159292. Acesso em 01/11/2020

PASSOS, Luiz Augusto. Fundamentos de Filosofia. Os caminhos do "pensar" para quem. Brasília-DF: CNTE, 2008.

PINHEIRO, Fernanda Vasconcelos. Porta dos Fundos: a construção de um produto em meio digital. Monografia submetida à Escola de Comunicação da Universidade Federal do Rio de Janeiro, como requisito parcial para obtenção do título de Bacharel em Comunicação Social, habilitação em Jornalismo. Rio de Janeiro: Universidade Federal do Rio de Janeiro, 2013.

REDAÇÃO. Ataque ao Porta dos Fundos: As polêmicas do especial de Natal e repercussão internacional. Revista Rolling Stone. Disponível em: https://rollingstone.uol.com.br/noticia/ ataque-ao-porta-dos-fundos-polemicas-do-especial-de-natal-e-repercussao-internacional/. Acesso em 01/11/2020.

Submetido em 23 de abril de 2021

Aceito em 15 de maio de 2021

Publicado em 8 de julho de 2021 